\title{
GAMES EM INVESTIGAÇÃO: LENDO IMAGENS EM UMA LAN HOUSE
}

Débora da Rocha Gaspar, Universidade Federal de Santa Catarina ${ }^{1}$

\section{Resumo}

A leitura de imagens de jogos eletrônicos é o tema apresentado neste artigo. Aqui constam os dados de uma pesquisa desenvolvida para o Programa de Pós-Graduação em Educação da Universidade Federal de Santa Catarina, cujos sujeitos são estudantes que estão concluindo a Educação Básica no Colégio de Aplicação da UFSC. O principal referencial teórico é uma abordagem de leitura de imagens desenvolvida por Sandra Regina Ramalho e Oliveira, a partir da Semiótica Discursiva.

Palavras-chave: Leitura de Imagens, Jogos Eletrônicos, Ensino de Arte.

\section{Abstract}

The topic presented in this article is the reading of images in electronic games. The article contains the data of a research developed for the Education Post Graduate Program at Universidade Federal de Santa Catarina, whose subjects are students that are finishing Middle School at Colégio de Aplicação, at UFSC. The main theoretical framework is an image reading approach developed by Sandra Regina Ramalho e Oliveira, from the perspective of Discursive Semiotics.

Keywords: Eletronic game; Reading of image; Arte class.

\footnotetext{
${ }^{1}$ Professora de Artes Visuais do Colégio de Aplicação da Universidade Federal de Santa Catarina e Doutoranda do Programa de Pós-Graduação em Arte e Educação da Universidade de Barcelona, España.
} 


\section{Game Play}

Há mais de quatro décadas os jogos eletrônicos fascinam adultos e crianças em várias partes do mundo. Até o início dos anos 2000, a maioria das pesquisas desenvolvidas no âmbito da Educação sobre essa mídia, preocupava-se em verificar se ela era "boa" ou "ruim" para as crianças e adolescentes, ou se seu conteúdo violento seria um desencadeador de atitudes agressivas, ou ainda, se teria um efeito de catarse. Entretanto, a preocupação deste estudo não é qualificar os jogos eletrônicos, na dicotomia "herói" ou "vilão". O objetivo foi verificar se os estudantes que estão concluindo a Educação Básica analisam os elementos da linguagem visual para lerem as imagens dos jogos eletrônicos, que costumam jogar em seu cotidiano.

Portanto, foi selecionada uma abordagem de leitura de imagem cujo marco teórico é a Semiótica Discursiva, desenvolvida por Ramalho e Oliveira (1998) para o âmbito educativo, que consiste em analisar o texto visual, partindo de sua expressão para chegar aos efeitos de sentido, possibilitando, no caso deste estudo, uma coleta e análise de dados focada na própria imagem.

A reflexão que parte Ramalho e Oliveira está relacionada ao problema do acesso aos bens estéticos, pois diante do imenso acervo de imagens produzido pela humanidade, no qual as imagens dos jogos eletrônicos se inserem, inúmeras pessoas mostram-se destituídos de um referencial mínimo para sua leitura; consequentemente, acabam sendo impedidos de acessar ao seu conteúdo (RAMALHO E OLIVEIRA, 2005, p.430). Desta forma, sem o conhecimento do funcionamento dos códigos imagéticos, a autora adverte para duas possibilidades ao cidadão: ou as pessoas não serão capazes de fazer sua tradução, sendo a elas, neste caso, sonegados conhecimentos, ou farão uma leitura intuitiva, talvez equivocada (RAMALHO E OLIVEIRA, 1998, p.04).

O eixo principal da abordagem de leitura adotada para esta pesquisa permite penetrar na complexidade da imagem por meio da sua desconstrução, pois desta forma melhor se percebe seu plano de expressão, ou seja, tudo aquilo que é perceptível ao olhar, o que irá fornecer os subsídios necessários para a compreensão no plano do conteúdo. Sabe-se que os planos de expressão e de conteúdo da imagem são indissociáveis; no entanto para efeito de estudo aqui são apresentados separadamente. O plano de expressão, segundo o modelo de análise adotado, subdivide-se em elementos constitutivos (ponto, linha, plano, cor, superfície, textura e dimensão, basicamente) e procedimentos relacionais (simetria, contraste, ritmo, movimento, entres outros). 


\begin{abstract}
Para clarear um pouco esta composição intrincada que é a imagem, poderemos fazer analogias, que são bastante simplistas, mas têm funcionado. Uma das comparações propõe pensar na imagem como um texto verbal, onde os elementos constitutivos seriam as palavras, e os procedimentos relacionais corresponderiam à sintaxe, ou seja, ao modo de organizar as palavras entre si. Mas é preciso cuidado, pois existem distinções para além do aspecto visual de ambos os textos. Uma delas é que nem a escrita nem a leitura da imagem são lineares; a outra é que cada elemento não "concorda" com apenas um outro elemento, como já foi mostrado acima; ao contrário, ele geralmente está articulado com diversos elementos, como que formando uma teia. Ou um rizoma. (RAMALHO E OLIVEIRA, 2005, p.433).
\end{abstract}

O primeiro passo para analisar uma imagem, consiste na busca de sua estrutura básica, na linha ou linhas que determinam a macroestrutura da imagem visual. Isto porque a estrutura básica da imagem vai dar sustentação à composição visual no seu todo e, portanto, será fundamental no jogo de articulação dos significados (RAMALHO E OLIVEIRA, 2005, p. 432). Em seguida, traçam-se esquemas visuais, buscando os contornos das figuras, separando figura do fundo, destacando rebatimentos e contrastes, principalmente entre linhas. Estas são apenas algumas possibilidades dos esquemas visuais, já que eles dependem tanto da imagem quanto do seu leitor; não há uma normas, nem sequer diretrizes, portanto, e podem ser elaborados tantos esquemas visuais quantos o destinatário da imagem achar necessário para sua análise.

Parte-se, então para a identificação dos elementos constitutivos, como linhas, pontos, cores, planos, formas, luz, dimensão, volume, textura. Ressaltam-se também, outros três elementos que não constituem a imagem, mas que geram efeitos de sentido, como o suporte, o recorte e a moldura. Convém lembrar que quando se fala em "moldura", é no sentido amplo, não só aquela madeira ou metal, decorado ou pintado, mas tudo o que está em torno, que dialoga com a obra (RAMALHO E OLIVEIRA, 2005, p.432).

Depois de identificados os elementos constitutivos, buscam-se as articulações entre eles, que são chamadas procedimentos relacionais. Essas relações podem ser encontradas entre elementos, entre elementos e bloco de elementos, entre blocos de elementos entre si; também um mesmo elemento pode estar articulado de modos diferentes (RAMALHO E OLIVEIRA, 2005, p.433).

Ramalho e Oliveira propõe um percurso que transita do todo da imagem para suas partes e vice-versa, num caminhar incessante, desvelando os elementos constitutivos e procedimentos relacionais do plano de expressão para chegar ao plano de conteúdo.

São as inúmeras trilhas que se entrecruzam no visível da imagem (plano 
de expressão) ao mesmo tempo em que tecem a significação (plano do conteúdo); daí a necessidade de observar minuciosamente toda a imagem, resgatando pontos relevantes para, a partir deles, recriar, traduzindo uma teia de elementos e procedimentos significantes que, como tal, é construída por meio de linhas paralelas, concêntricas, todas relacionadas (RAMALHO E OLIVEIRA, 2005, p.434).

Tais procedimentos são necessários para se chegar aos sentidos de um texto imagético. Todavia, a autora ressalta que não se deve considerar seus elementos constitutivos como um vocabulário auto-suficiente, uma vez que eles não adquirem sentido no isolamento, mas sempre e somente na relação. A descoberta dessas relações vai conduzir o leitor aos efeitos de sentido, ou ao plano do conteúdo (RAMALHO E OLIVEIRA, 2005, p.434-435). A síntese de sua proposta pode ser visualizada do seguinte modo:

I - Escaneamento visual da imagem, buscando a estrutura básica da composição;

II - Desconstrução da cor e destaque às linhas, na elaboração de esquemas visuais;

III - Redefinição dos elementos básicos constitutivos;

IV - Busca dos procedimentos relacionais, estabelecidos entre os elementos;

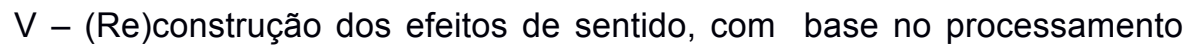
dos procedimentos;

VI - Trânsito incansável entre elementos, bloco de elementos, procedimentos, todo e partes, esquema visual e imagem;

V - Dados de identificação da imagem (RAMALHO E OLIVEIRA, 2005, p.435).

Esta abordagem de leitura de imagem tem como referencial teórico a Semiótica Discursiva que se origina nos estudos do suíço Ferdinand de Saussure, considerado o pai da linguística. Saussure estudou a vida dos signos no seio da vida social (SAUSSURE, 1969, p. 24), dedicou-se apenas à linguagem verbal e somente vislumbrou a possibilidade de aplicação de alguns de seus princípios em outras linguagens:

apresentando-se assim a linguagem como um dos fundamentos das sociedades humanas, não era difícil prever que a teoria linguística acabaria por ser solicitada a prestar contas do que ocorria em outros campos gerados e sustentados por aquela matriz fundamental: o campo da arte, da arquitetura, do cinema, do teatro, da psicanálise, da sociologia e outras áreas. 
É o que nos diz Teixeira Coelho (1983, p.15-16), não sem chamar a atenção para o fato de que, para estas adaptações acontecerem, seria necessário um grande percurso em seus estádios de desenvolvimento. É claro: a gramática, com suas regras, é fundamental na linguagem verbal, ao passo que a quebra de paradigmas é um dos modos de se manifestar mais expressivos das demais linguagens estéticas, mesmo da linguagem verbal, como é o caso de quando ela, por se tornar estética, quebra normas gramaticais. Tratam-se das licenças poéticas, na linguagem em versos, por exemplo, ou seja, o "direito" que as linguagens estéticas têm, aquele de usar a "linguagens" de modos inesperados, originais, fora de convenções.

Vários discípulos seguiram as proposições de Saussure, revendo-as, alterando-as, enfim, desenvolvendo os pressupostos da linguística em diversas direções e sentidos. Destacam-se Louis Hjelmslev, Roman Jakobson e Algirdas Julien Greimas.

Hjelmslev foi o responsável pela substituição dos termos significado e significante, palavras hoje ainda usadas como clássicas referências ao corolário de Saussure por, respectivamente, plano de conteúdo e plano de expressão. Desta forma, o semioticista dinamarquês Louis Hjelmslev (1899-1965) denominou assim as duas dimensões do texto, plano de expressão e plano de conteúdo, os quais mantêm uma relação de interdependência, ou seja, a forma de conteúdo e a forma de expressão são duas constantes que dependem uma da outra como o verso e anverso da metáfora saussureana (NÖTH, 1996, p.59), planos estes que podem ser separados, provisoriamente, para efeitos de análise como no caso deste estudo. Hjelmslev, por meio de seus desenvolvimentos teóricos na trilha de Saussure, contribuiu para as discussões lideradas por A. J. Greimas na chamada École de Paris.

Algirdas Julien Greimas (1917-1992), juntamente com seu grupo, diversificou os estudos de significação e extrapolou para além do verbal, e assim seu projeto semiótico influenciou estudos na pintura, na moda, no cinema, na teologia, na arquitetura entre outras áreas do campo semiótico, uma vez que o principal objetivo de sua teoria é estudar $o$ discurso com base na ideia de que uma estrutura narrativa se manifesta em qualquer tipo de texto. (NÖTH, 1996, p. 145). É claro que esta estrutura narrativa não é a mesma para qualquer texto e linguagem, pois cada categoria de produto industrializado, por exemplo, terá a sua. Por outro lado, cada texto criativo, cada criação estética, visual, verbal, musical ou cênica, terá a sua própria estrutura. A estrutura é inerente a seres humanos e aos animais, que têm seu corpo assentado sobre uma estrutura óssea; e às pontes e aos 
edifícios, entre outras construções humanas, que não prescindem de uma estrutura de sustentação.

Greimas propõe, para o estudo do plano de expressão, formantes eidéticos, cromáticos e topológicos, categorias referentes aos elementos mínimos de significação, as unidades discretas que, no caso do texto imagético, são formas, cores, bem como sua situação no espaço da manifestação.

\begin{abstract}
A teoria dos formantes que, apesar do voto de Hjelmslev, não se acha ainda constituída em linguística, deveria encontrar aqui seu lugar. Vê-se bem que a constituição dos formantes por ocasião da semiose não é outra coisa senão uma articulação do significante planar, não é senão o seu recorte em unidades discretas legíveis, tendo em vista uma certa leitura do objeto visual, que não exclui de modo algum - já o vimos a propósito da dupla função do alfabeto - outras segmentações possíveis do mesmo significante. As unidades discretas assim constituídas a partir de traços são já bem conhecidas: são "formas" no sentido da Gestalttheorie, são "figuras do mundo" no sentido que Ihes dá G. Bachelard, são "figuras do plano da expressão" como que Hjelmslev (1984, p. 8).
\end{abstract}

Greimas (1984) afirma que os formantes ou categorias eidéticas são aquelas que estão encarregadas de estabelecer a discrição das diferentes unidades do significante, já os formantes ou categorias cromáticas são as que se embasam em apreensões individuantes dos termos. No entanto, as categorias topológicas

"retilíneas" umas (como alto/baixo ou direito/esquerdo), "curvilíneas" outras (como periférico/central ou circunscrevente/circunscrito) bem como seus derivados e compostos, crivam, partindo daquilo que ela não é, toda a superfície enquadrada traçando aí os eixos e/ou delimitando as regiões ("plages"), cumprindo com isso dupla função, a de segmentar eventuais percursos sobre os quais se acham dispostos os diferentes elementos de leitura (GREIMAS, 1984, p. 9).

Greimas trabalhou em conjunto com distintos estudiosos, formando um grupo interdisciplinar, e dada as formações específicas de cada membro da École de Paris, foi possível avançar a produção não só na pesquisa básica, mas também na pesquisa aplicada, e esta, em distintas áreas da atividade humana. Entre os pensadores que deram continuidade aos aprofundamentos daquele grupo destacam-se Eric Landowski, Jacques Fontanille e Jean-Marie Floch.

Hoje se fala em semio-estética, uma expressão cunhada por Jean-Marie Floch para 
denominar os estudos que entrelaçam conhecimentos da semiótica com os da estética, ou mais particularmente, da semiótica com os da visualidade. No Brasil, os estudos de Floch foram seguidos por Ana Claudia de Oliveira e Sandra Ramalho e Oliveira, sendo que a última assim se expressa em relação a ele:

Jean-Marie FLOCH, semioticista francês, nasceu (...) em 1947, e faleceu, precocemente, em 2001, aos 54 anos. Colaborador de A. J. Greimas, Floch dedicou-se ao estudo das linguagens visuais. Em duas de suas publicações, quais sejam, Identidades Visuais e Semiótica, Marketing e Comunicação, ambas não traduzidas ainda para o português, Floch adotou, ainda que com a roupagem semiótica, paradigmas propostos por Wölfflin, para a busca da compreensão da arte e de imagens estéticas: o clássico e o barroco (RAMALHO E OLIVEIRA, 2004, p. 185-186).

Para Ana Claudia Oliveira, a divisão do plano de expressão se dá em formantes eidéticos (forma), cromáticos (cor) e topológicos (organização no suporte); mais adiante, acrescentou a esses três mais uma categoria, a dos formantes matéricos, conforme o texto "Lisibilidade da imagem" em que afirma que (...) uma imagem, uma semiótica plástica, é formada no plano da expressão pelo material e as matérias que lhe dão existência visiva (formantes matéricos) (OLIVEIRA, 2001, p.6). Percebe-se que, na arte contemporanea, os materiais utilizados a construção das imagens influenciam decisivamente a apreensão dos efeitos de sentido, no campo das artes visuais, o que determinou a necessidade de atenção a esta categoria, a do formante matérico.

Para a semio-estética, ou seja, para a linha teórica, no contexto da semiótica discursiva, que se dedica à visualidade, uma imagem também é considerada um texto, um enunciado, uma manifestação ou um discurso, o que implica que toda a imagem é um tecido onde a significação é tramada. A imagem, segundo esta linha teórica da semiótica, pode ser denominada enunciado, o seu autor, o enunciador, e aquele que a "traduz", elaborando significados a partir dos efeitos de sentido do texto visual, o enunciatário, que é o destinatário da enunciação. Assim o discurso visual manifesta-se no plano da expressão, por meio de imbricamentos na tessitura do nível de expressão, esses formantes se interrelacionam e, em feixes, e não formante e formante, ou seja, termo a termo, correspondem a categorias do plano do conteúdo (OLIVEIRA, 2001, p.7).

Desta forma, a significação de um texto se dá na relação entre os planos de expressão e o de conteúdo e destes com cada enunciatário específico, pois é ele que 
articula os planos nas mas nas relações complexas e diversificadas geram efeitos de sentido. Para tornar possível o estudo desse intrincado fenômeno que é a imagem, a semiótica visual propõe instrumentos de descrição e análise, contribuindo expressivamente para as pesquisas desenvolvidas acerca do fenômeno da significação em textos imagéticos.

\section{Preparando o jogo investigativo}

A pesquisa de campo foi realizada em duas etapas. Na primeira aplicou-se um questionário para todos os alunos do terceiro ano do Ensino Médio do Colégio de Aplicação da UFSC, campo da investigação. Na segunda etapa foram realizadas entrevistas, em uma lan house, com os estudantes que afirmaram no questionário que costumam fazer screenshots enquanto estão jogando. Os screenshots são imagens fixas do jogo, fotografias que os jogadores fazem, geralmente, para mostrar aos demais seus desempenhos na partida.

As entrevistas realizadas com os estudantes na lan house se constituíram em conversas individuais, filmadas e gravadas para posterior transcrição. Formulou-se um roteiro de perguntas que conduziu a entrevista. Para tanto, foi usado como referencial os mesmos passos da abordagem de leitura de imagem desenvolvida por Ramalho e Oliveira (1998), que são os seguintes: 1) um olhar geral para a imagem; 2) Reconhecer a estrutura básica da imagem; 3) Construir o esquema visual da imagem; 4) Identificar os elementos constitutivos da linguagem visual presentes na imagem; 5) Identificar os procedimentos relacionais presentes na imagem; 6) Chegar aos efeitos de sentido da imagem. Tais etapas configuram os diferentes momentos da entrevista com os estudantes, conforme o seguinte roteiro: Um olhar geral para a imagem (a) Antes de iniciar o jogo, deve-se pedir ao aluno(a) que ao longo da partida selecionar uma cena para "fotografar", um screenshot; b) Enquanto joga deixar o aluno falar livremente sobre o jogo e suas imagens; c) Após, terminada a partida, olhar o screenshot (fotografia da cena selecionada durante o jogo) e perguntar o motivo de ter selecionado essa imagem; d) Instigar o aluno a comentar livremente acerca da imagem selecionada); Estrutura básica da imagem (você identifica linhas ou formas que podem não estar evidentes, mas que formam a estrutura básica dessa imagem?); Esquema Visual (abrir o screenshot selecionado pelo aluno em um programa de edição de imagem para ele retirar da imagem as linhas principais que a compõe.); Elementos constitutivos da linguagem visual (Quais são os elementos da linguagem visual (ponto, linha, textura, dimensão, cor, volume, ...) que compõem essa 
imagem? Conduzir a conversa fazendo com que o aluno aponte na imagem onde se encontram os elementos e de que maneira estão sendo utilizados); Procedimentos relacionais (Como os elementos que compõem essa imagem estão articulados? Você observa ritmo, contraste, simetria, equilíbrio... ? Conduzir a conversa fazendo com que o aluno aponte na imagem onde se encontram os elementos e de que maneira estão sendo utilizados); Efeitos de sentido ou significação (agora que você já falou bastante dessa imagem, o que ela está dizendo? O que significa essa imagem?)

Convém ressaltar que para manter o sigilo da identidade dos estudantes foram selecionadas, aleatoriamente, cores para identificá-los: Vermelho, Azul, Verde e Roxo. Antes de iniciar a partida, os estudantes tiveram total liberdade para selecionar o game que gostariam de jogar. Como estávamos em uma lan house, por sugestão de um dos estudantes, três deles resolveram jogar juntos e selecionaram MU, um jogo eletrônico em 3D, da categoria MMORPG, produzido pela Webzen. A narrativa do jogo se passa num universo medieval. MU era um lugar fértil e próspero, mas que se tornou caótico devido às lutas entre os senhores feudais. Neste contexto, Antonias, um homem mau e ambicioso se entregou aos desejos de Lemulia, a feiticeira maligna, e libertou Kundun que pretende dominar a Terra e escravizar a humanindade. Com a ascensão de Kundun ao poder, ele trouxe seus asseclas que esconderam o selo de Etramu, a única forma de deter o demônio. Para proteger o selo o dividiram em 8 partes, cada uma delas vigiadas por criaturas monstruosas. O desafio do jogo é encontrar heróis que consigam aprisionar Kundun com o selo de Etramu, para que o mundo volte a ser livre. Em MU o jogador tem a opção de ser um Cavaleiro Negro (Dark Knight), Fada/Elfa (Fairy/Elf), Feiticeiro Negro (Dark Sorcerer) e Gladiador Mago (Magic Gladiator), para lutar pela liberdade de MU. Cada uma dessas classes de personagens apresenta características próprias para lutar e seguir as aventuras no mundo de MU. No entanto, o jogador pode selecionar suas vestimentas, suas armaduras, escudos entre outros apetrechos que irão ajudá-lo no desenvolvimento do jogo. Este diferencial de equipar seu avatar com inúmeras combinações de itens foi ressaltada por Azul como um fator que o levou a selecionar este game. Quando questionado o que o atraia nesse jogo, ele respondeu:

Sei lá! Tipo ele tem ... sei lá! O design dele é bom, tipo não é como outros RPG que é bem ruim o gráfico. Ele tem uma qualidade de imagem, ele tem ... sei lá! Ele tem bastantes opções, quando, tipo mostra armadura, tem um design da armadura, tipo coisas do personagem, já outros jogos de RPG não tem isso, por isso eu escolhi esse pra jogar. 
Apenas Vermelho quis jogar o clássico Tibia, pois é o game que vem jogando ultimamente, costuma jogá-lo com seu irmão. Este jogo é um RPG, cujo objetivo, segundo Vermelho, é ir matando animais, quanto mais animais matar mais experiência ganha para matar animais cada vez mais fortes. Tibia é um MMORPG (Multi Massively Online Role Playing Game), que se passa num universo medieval em que os jogadores podem interagir diretamente uns com os outros e com o mundo do jogo. Seus gráficos são em duas dimensões, a tela principal do jogo apresenta uma vista superior, mostrando toda a área próxima ao jogador. Tibia não possui um objetivo predeterminado a ser alcançado ou um final: os jogadores determinam a forma como desejam seguir as suas aventuras, e o mundo continua existindo e mudando mesmo que os jogadores não estejam lá. Quando um jogador entra no mundo, ele é representado por um avatar virtual, um personagem que representa aquele jogador. Tudo o que acontece com um jogador é registrado no servidor em tempo real, assim, quando ele voltar, o seu personagem estará com os mesmos atributos e características de quando o jogador saiu. Cada personagem inicia a sua jornada em uma ilha introdutória chamada Rookgaard. Nela eles podem aprender os fundamentos do jogo, como: lutar contra monstros, manipular o personagem e objetos, adquirir e comprar itens, entre outras possibilidades. Os personagens vão ficando mais fortes à medida que lutam. Cada vez que derrotam um monstro eles ganham pontos de experiência (dependendo da força do oponente derrotado). Quando um personagem atingir certo número de pontos de experiência, este avança de nível; o nível é um dos fatores que determina a força do personagem. Os personagens podem sair da ilha de Rookgaard a partir do nível oito, e então explorarem o restante do mundo. Ao saírem da ilha, os personagens devem escolher uma cidade natal (que pode ser mudada mais adiante) e uma vocação: Knight (cavaleiro); Sorcerer (feiticeiro); Druid (druida); Paladin (paladino), mas uma vez que escolherem sua "profissão" não podem mais mudar. Não é possível para um personagem viajar de volta à Rookgaard uma vez que ele saiu dela.

Um fator interessante na escolha dos jogos é que Tíbia possui gráfico em duas dimensões, visto em terceira pessoa, já MU em três dimensões, mas também tem o mesmo ponto de vista. No entanto, o tratamento visual em MU é mais rico em detalhes e de maior definição que Tíbia. Os dois games são do mesmo gênero MMORPG (Multi Massively Online Role Playing Game).

Outro fator que chamou atenção foi a afirmação de Roxo, que comentou que ele, Verde e Azul costumam jogar juntos, mas em ambientes distintos. Como MU é via internet, eles não necessitam estar no mesmo lugar "real", como em uma lan house, mas se encontram no mesmo espaço virtual. Tal fator chamou a atenção da pesquisadora para as 
conversas que os participantes realizavam enquanto jogavam.

\section{Imagens de Games: analisando os screenshots}

\subsection{Entrevista com Vermelho}

Acerca da escolha da imagem, Vermelho comentou que queria registrar uma ação de êxito, com alto grau de dificuldade, matar dois monstros ao mesmo tempo. Porém, ao observar a imagem que havia realizado, se deu conta que o "foguinho" que irradiava dos avatares e indicava o êxito de sua jogada, não ficou registrado na imagem. Vermelho, diferente de seus colegas, fez uma única imagem, devido à dificuldade de fazer screenshot no jogo que selecionou, Tíbia. E quando questionado sobre a estrutura básica da imagem afirmou considerar a linha de contorno como o eixo principal.
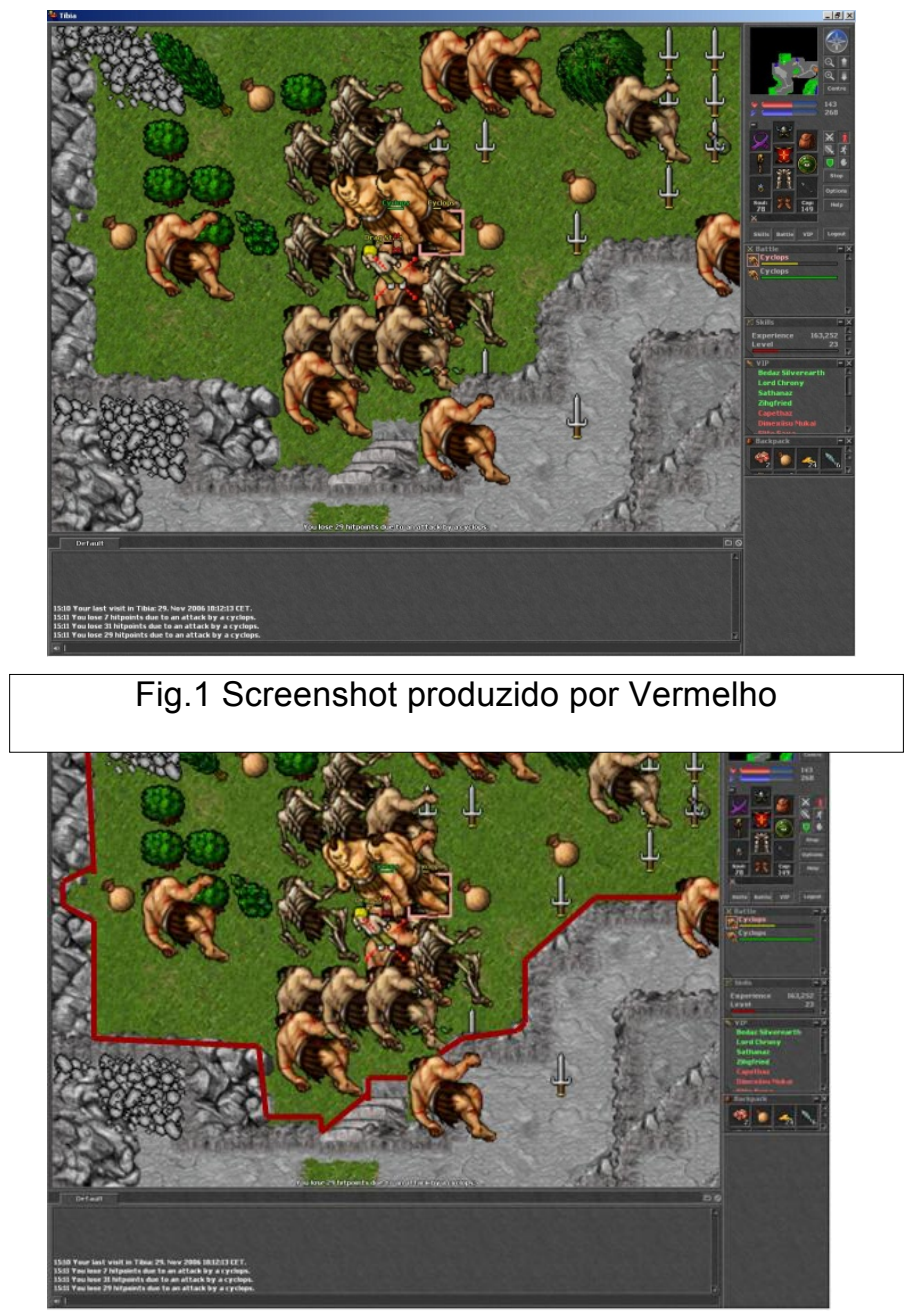


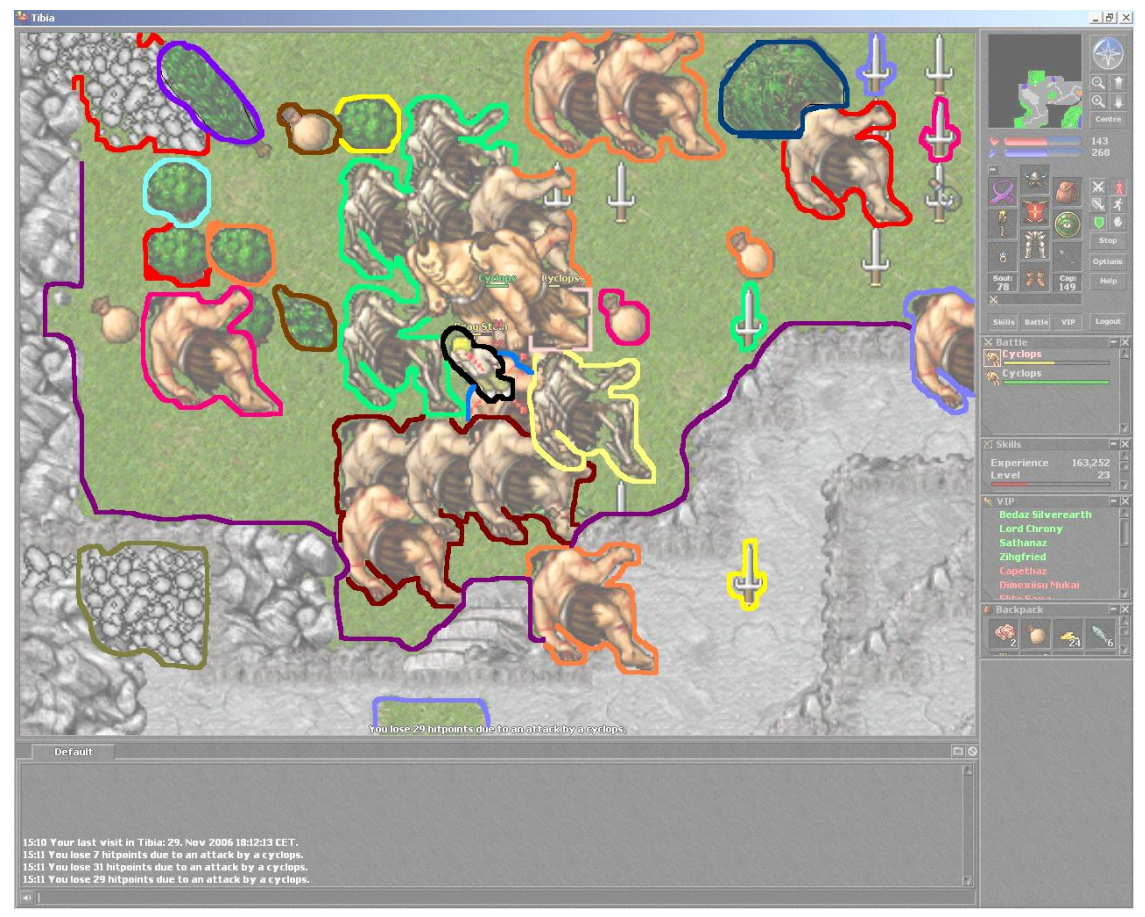

Fig. 3 Esquema Visual produzido por Vermelho

Antes de iniciarem a leitura foi solicitado a todos os participantes que realizassem o esquema visual dos screenshots, todos usaram o programa "Paint" para fazê-lo. Desta forma, antes mesmo de iniciar a leitura, enquanto faziam os esquemas visuais, os estudantes tiveram a oportunidade de se aterem mais aos detalhes no momento de salientar suas linhas.

Vermelho foi o primeiro a fazê-lo, optou por utilizar inúmeras cores para representar cada objeto ou personagem. Quando questionado sobre os elementos constitutivos presentes em sua imagem, Vermelho diz que não identifica que o modo como a linha é usada pode gerar textura. Porém, ao se referir ao gráfico atual do game em relação ao anterior, Vermelho afirma que a textura foi melhorada, alterando a presentificação do que seria grama e pedra. Como consegue identificar o sentido que a textura se refere, Vermelho afirma que o jogo não é "tão pobre assim" em relação a esse elemento.

Vermelho quando questionado sobre os procedimentos relacionais analisa a construção da imagem, mas inicialmente emitiu juízo de valor, “(...) é bom, porque (...)” , todavia não Ihe foi perguntado se os recursos visuais foram utilizados de modo bom ou ruim. Vermelho afirma ainda que: acredito que tem uma harmonia nas cores, na hora que 
eu vejo nada me dói o olho, digamos assim neh! Pôde-se observar nas palavras de Vermelho que este consegue fazer mais articulações com os procedimentos relacionais do que com os elementos constituitivos da linguagem visual.

O último questionamento da entrevista foi sobre o significado da imagem. Vermelho quando questionado afirma: Ô! Eu estou morrendo. (risos). Então, perguntou-se o porquê ele afirmava que estava morrendo, sua resposta foi: Por quê? Porque eu estou tomando "hit". Como não se sabia o que seria um "hit", foi pedido que explicasse o que seria: Hit é porrada. (risos) Eu estou tomando hit de dois monstros ao mesmo tempo, isso na verdade é uma coisa ruim, neh!

\subsection{Entrevista com Azul}

As imagens que Azul, Verde e Roxo selecionaram apresentam o mesmo efeito de ataque, em forma de estrela amarela brilhante no chão, no entanto Azul justifica sua escolha pelo contraste deste efeito com seu personagem e por estar lutando com Verde. E descreve a estrutura básica de sua imagem assim: Deixa eu ver... uma linha pro personagem aqui, uma linha para a estrela aqui assim, uma estrela mais ou menos aqui pra fazer o ataque dele e as linhas horizontais aqui pro cenário.

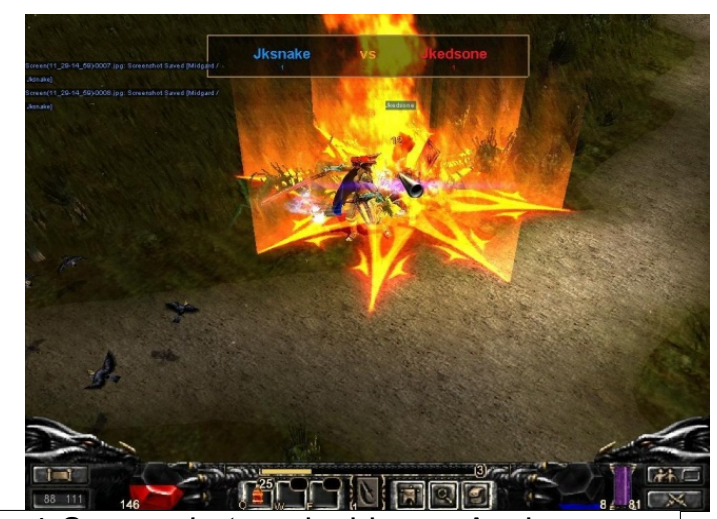

Fig. 4 Screenshot produzido por Azul

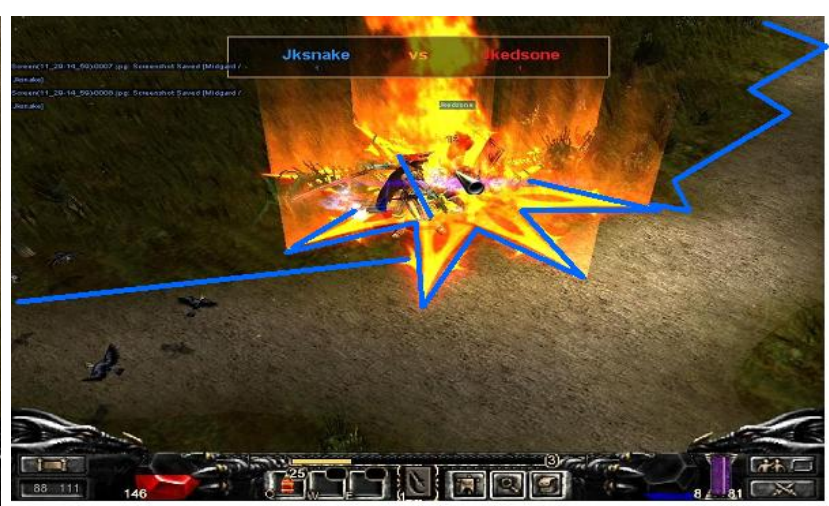




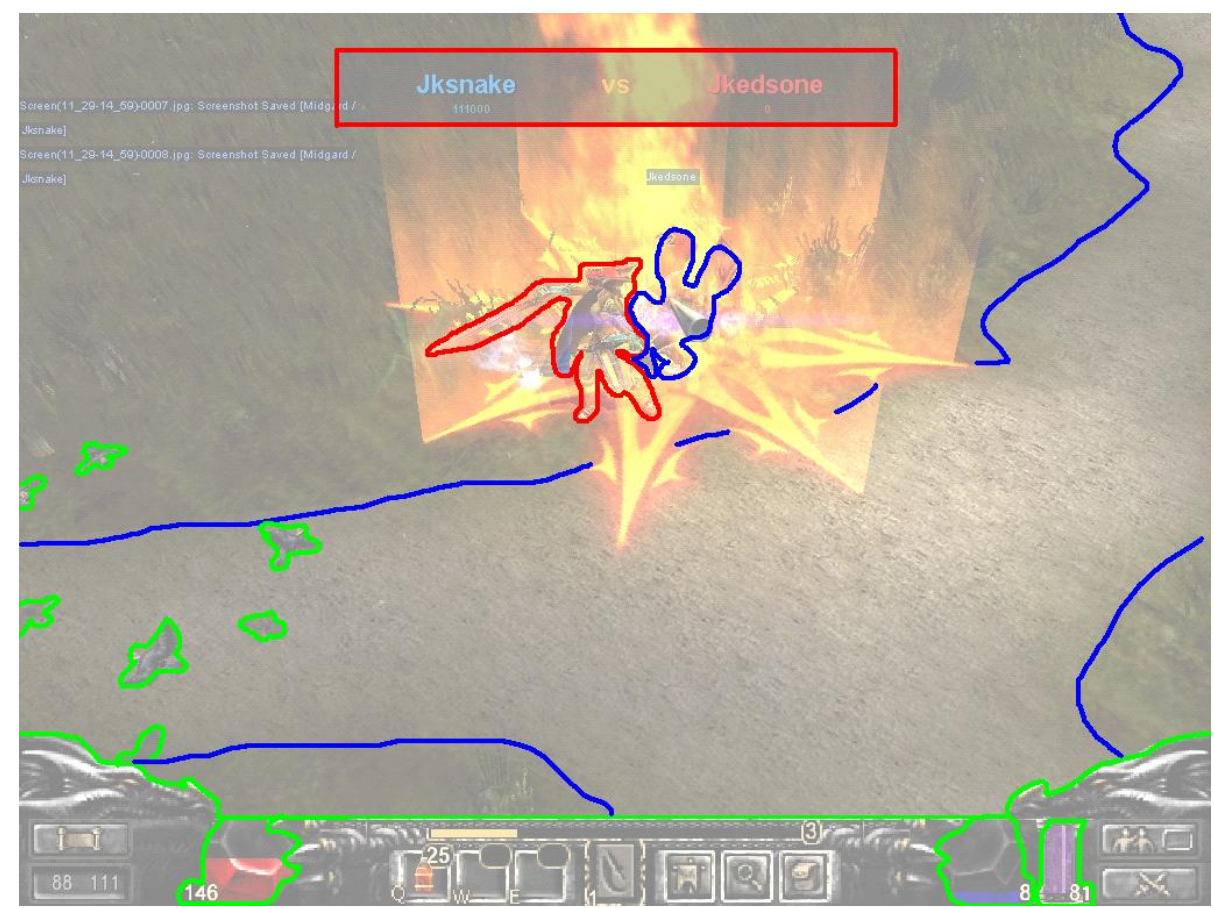

Fig.3 Esquema Visual produzido por Azul

Olhando para seu esquema visual, Azul é questionado acerca dos elementos constitutivos da linguagem visual. O elemento ressaltado por Azul é a cor, mais especificamente as diferenças de tons, ou segundo ele, o contraste de cor. Pois para Azul não existe uma linha de contorno e sim a diferença de cor entre o laranja do ataque e o verde da vegetação. No que se refere aos procedimentos relacionais Azul ressalta a simetria das armaduras e também do ataque: é o próprio ataque, aqui assim ele é simétrico, todos os negócios são iguais só muda a posição aqui, aqui também é igual. Volta a falar do contraste de cores.

Quando questionado sobre o sentido de seu screenshot Azul quis saber se seria para falar usando seus conhecimentos sobre o jogo ou como se não conhecesse, então foi pedido que ele falasse dos dois modos. O significado da imagem para Azul é o ataque, percebe que os recursos visuais indicariam esse sentido mesmo que ele não conhecesse o jogo e depois acrescenta que pela forma de presentificação do ataque ele sabe quem o fez, pois o ataque de seu personagem tem outra forma, racha o chão.

\subsection{Entrevista com Verde}

Verde justifica a escolha de seu screenshot pela composição da imagem: 
personagem centralizado e noção de movimento. Para ele a estrutura básica de sua imagem "seriam os personagens, se tu for ver, todos eles poderiam estar numa linha vertical. Esse mais atrás... esse...".

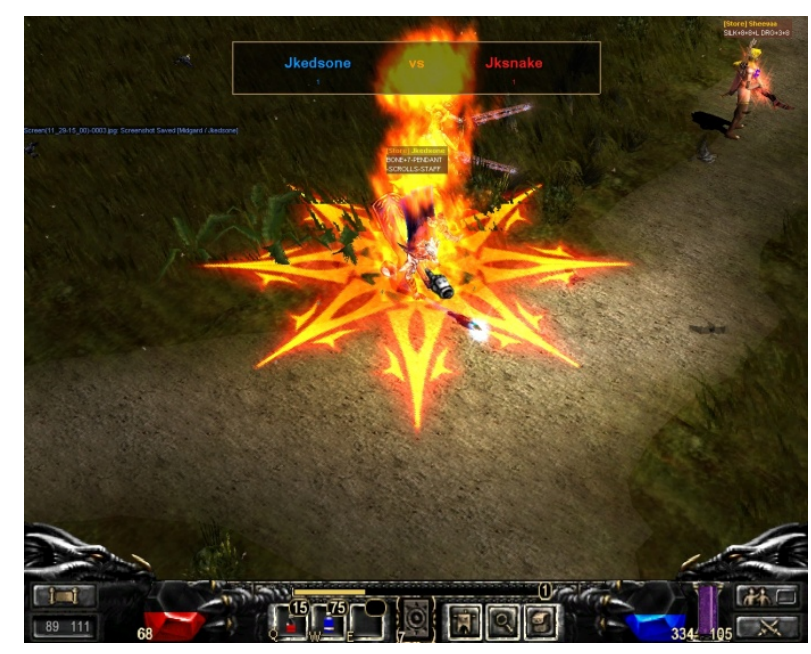

Fig. 7 Screenshot produzido por Verde

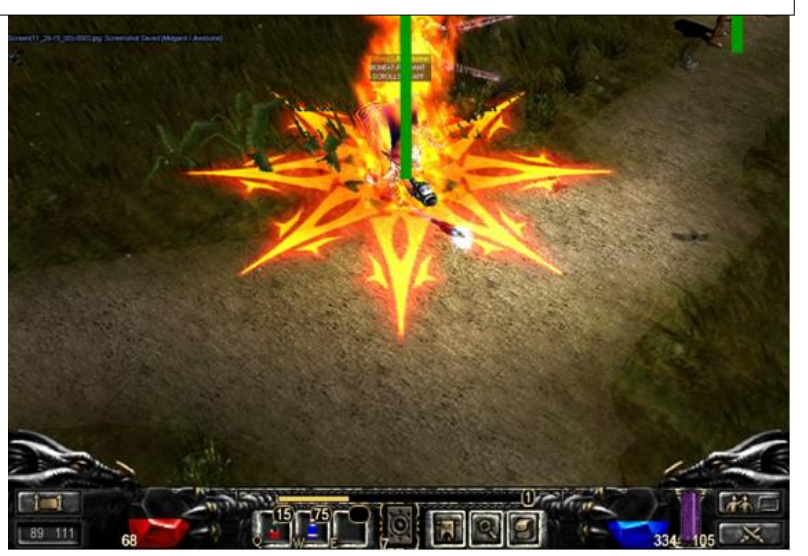




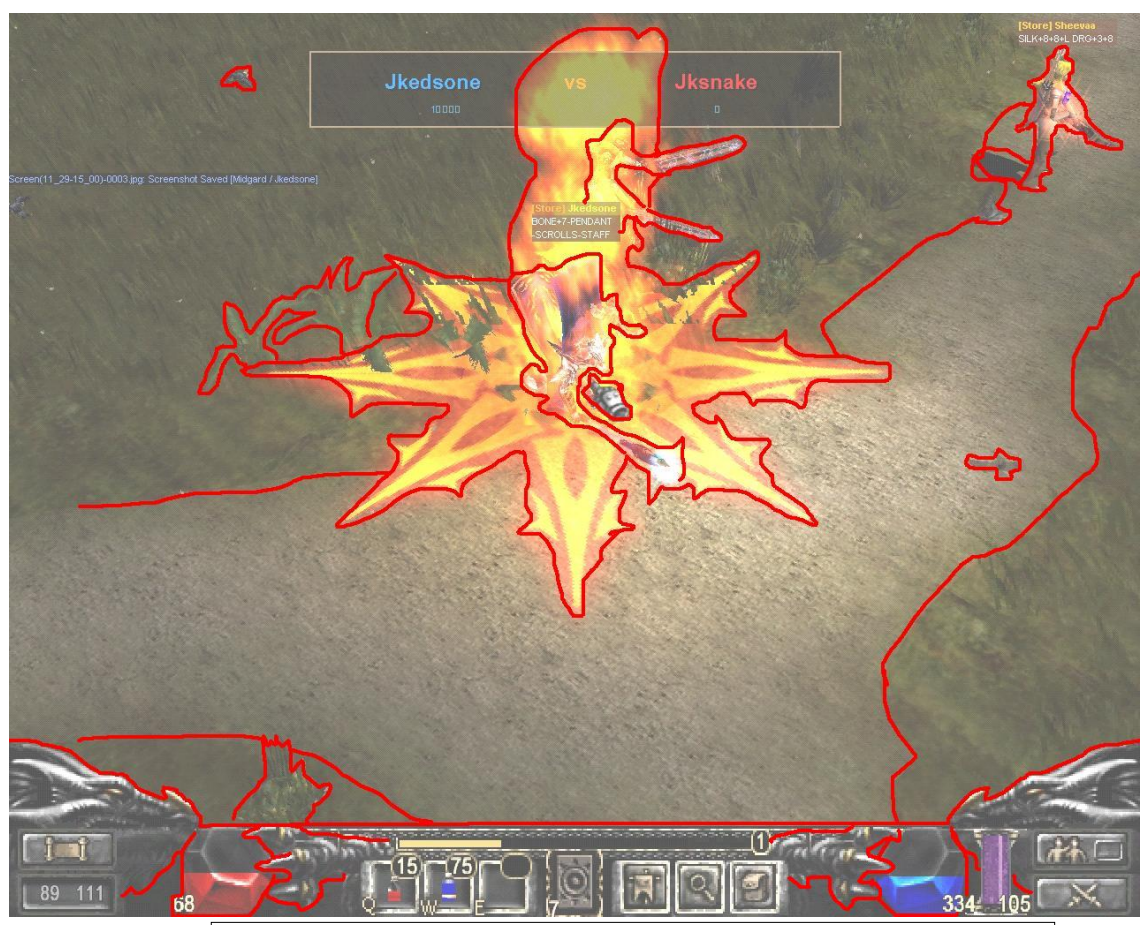

Fig.9 Esquema Visual produzido por Verde

Diante de seu esquema visual Verde foi perguntado quais tipos de linhas ele identificava, Verde considera que as "curvas poderiam ser a estrada que varia um pouco. As retas poderiam ser os personagens, como eu tinha falado e outras retas horizontais poderiam ser a barra que tem embaixo..." Verde descreve com mais detalhes a imagem, observa-se que ele percebe que a textura pode ser formada por linhas e diferença de tons, ressalta a noção de perspectiva, citando inclusive sua especificação, isométrica. Comenta sobre as formas e ressalta que todos esses recursos são utilizados para dar a "idéia de dimensionalidade", ou seja, de tridimensionalidade.

Acerca dos procedimento relacionais Verde destaca o movimento de seu screenshot, como se pode perceber em suas palavras:

\begin{abstract}
"Ah, acho que... o personagem que parece que ta caindo, o movimento dele dá a impressão de ele ta dando uma espécie, talvez, de soco no chão. $E$ isso dá uma noção de movimento. Ainda mais, porque ele tem meio que um rosto de fogo por cima dele. Dá a idéia que ele já esteve ali, já esteve naquela posição, agora ele ta em outra. E a estrela embaixo daria mais uma idéia de destino, pra onde ele iria. Talvez, a direção dele mostra pra onde seria esse movimento. Esse aqui mostra que ele ta virado pra direita, então esse seria o sentido dele".
\end{abstract}

Verde não faz afirmações fechadas, utiliza palavras como: "parece; "dá a impressão de"; "uma espécie de "; "dá uma noção de"; "dá a idéia de". Em todo seu 
discurso ele justifica a noção de movimento que ele ressaltou, descreve as características que dão esse sentido de movimento.

Para Verde o significado de sua imagem é luta, um personagem contra o outro. Justifica tal sentido através das indicações fornecidas pelo jogo e por meio do movimento e posição dos personagens.

\subsection{Entrevista com Roxo}

Roxo afirma ter selecionado o screenshot por aparecem os avatares dos três estudantes juntos (Azul, Verde e Roxo), todos lutando contra o mesmo inimigo, além de dois ataques que geram efeitos visuais distintos. Ele considera que a estrutura básica de sua imagem "não seria o contorno mas sim o brilho... o que tu vê assim, neh!"
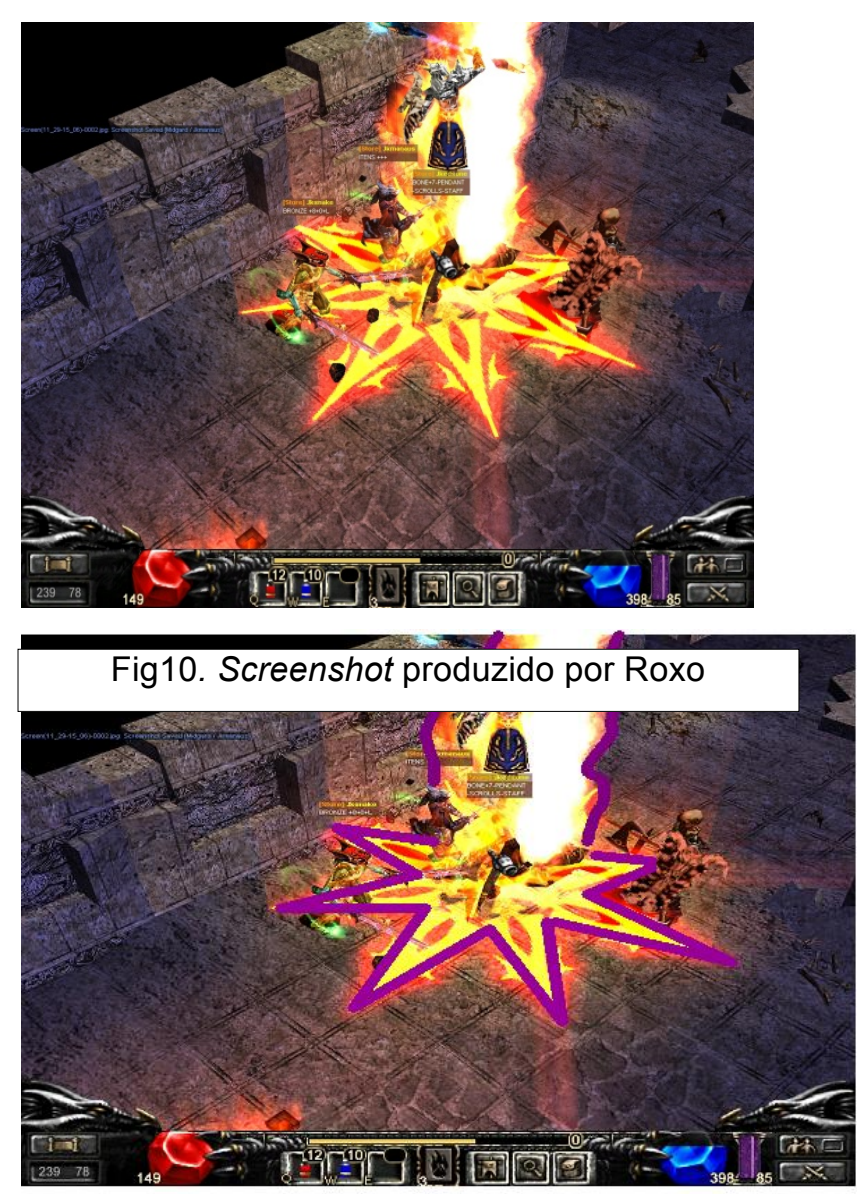


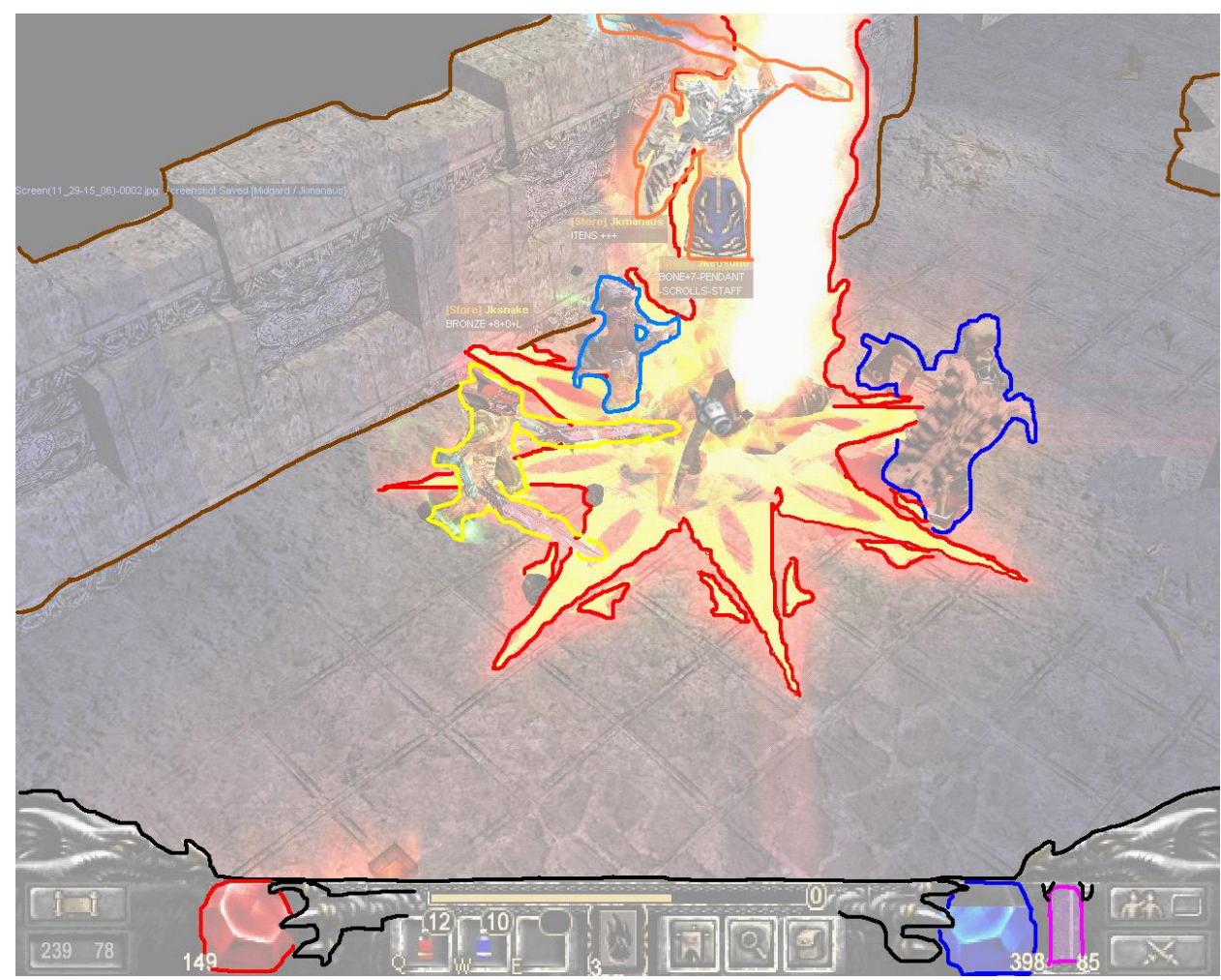

Fig.12 Esquema Visual produzido por Roxo

No que se refere aos elementos constituivos da linguagem visual, Roxo vai respondendo a partir dos exemplos que são dados na pergunta, ele reafirma o que se acabou de mencionar. Não parece ter segurança em suas argüições.

Roxo demonstra não ter compreendido o que são os procedimentos relacionais, primeiro pergunta se é para falar da linha da imagem, então voltou a chamar atenção para simetria, para ver se ele iria se desprender da linha. Ele diz que não havia reparado e depois diz que sim, que às vezes ela é simétrica, esse "ela" se refere à linha. Depois muda o eixo da conversa para as configurações do computador. Roxo não consegue visualizar na imagem os procedimentos quando questionado.

Ação foi o significado atribuído por Roxo a seu screenshot. Então, perguntou-se o que na imagem Ihe dizia que era ação o sentido principal, Roxo respondeu:

Acho que é a pose de batalha, também... aqui eu salto pra atacar o bicho... em volta, aqui, dele, por exemplo: eu atacando ele com fogo e ele espisoteando, não sei, acho que é. Dá uma imagem bem de ação. Assim de luta. 


\section{Reflexões sobre as leituras dos screenshots dos games}

Alguns termos usados na entrevista tiveram que ser explicados aos estudantes, pois não conheciam as nomenclaturas questionadas na entrevista, essa questão já havia sido prevista pela pesquisadora. Então, para explicar o que seria a estrutura básica de uma imagem foram oferecidas breves informações, feitas analogias com o Raio X e usado como exemplo um cartaz de jogo que estava diante dos estudantes na lan house. As descrições apresentadas pelos estudantes Vermelho, Azul e Roxo emolduraram o que seria o ponto de atenção da imagem.

Ao longo das entrevistas verificou-se que Vermelho, Azul e Verde não demonstram dificuldade em identificarem os elementos constitutivos. Azul fala de alguns preocedimentos relacionais como elementos. Mas é Verde que apresenta uma descrição mais consistente dos elementos na imagem selecionada. Porém, Roxo demosntra mais dificuldade em identificá-los, suas respostas não apresentam consistência na compreensão desses elementos.

Durante a observação dos estudantes jogando na lan house o MU, pôde-se perceber que aquele ambiente virtual de fantasia e lutas, se mostrou também um espaço colaborativo, em que eles se deixaram morrer para ajudar o amigo. Desta forma, o ato de "matar" se distância do conceito que se tem na "realidade", não é exterminar alguém, pois no jogo eles possuem muitas porções de vida. Tal observação vem ao encontro das conclusões da pesquisa de Alves (2005), que apoiada nos estudos da psicanálise, analisa a influência dos jogos eletrônicos e as possíveis implicações em comportamentos violentos, considerando, então, que o jogo eletrônico é um espaço de catarse.

De acordo com as entrevistas, pode-se concluir que Verde demonstra ter mais domínio dos conhecimentos estéticos específicos da linguagem visual que Azul e Vermelho, que demonstraram pouco conhecer. Já Roxo conhece pouquíssimo. Todavia, todos chegam aos efeitos de sentido da imagem. Eles foram diretos e pontuais ao abribuir significado a seus screenshots: Vermelho diz que está morrendo, Azul, Verde e Roxo que é luta. Mas só fazem relação do significado atribuído por eles com a composição da imagem quando questionados, isso demonstra a dificuldade dos estudantes em realizar a tradução da linguagem visual para a verbal. Apresentam, então, leituras superficiais, com visões aceleradas que podem levar a manipulação.

Convém lembrar que Verde, Azul e Vermelho estudaram no Ensino Fundamental no Colégio de Aplicação, em seus respostas percebe-se que eles já ouviram falar nos 
elementos constitutivos e procedimentos relacionais, não com essa nomenclatura, o que confirma como esta unidade de ensino desenvolve um trabalho diferenciado na área de Artes Visuais, se destacando da realidade brasileira, presentificada aqui por Roxo que veio de uma instituição de outro estado do país e quase nada sabia sobre os conhecimentos estéticos específicos da linguagem visual.

A preocupação com a leitura de imagens no Brasil, está presente desde a década de 1980, quando Ana Mae Barbosa divulga sua então "metodologia triangular", hoje Abordagem Triangular, na qual a aprendizagem em Arte se dá na relação entre o fazer artístico, a leitura da imagem e a contextualização. Tanto os Parâmetros Curriculares Nacionais (PCNs) como a Proposta Curricular de Santa Catarina (PCSC), também apresentam três eixos norteadores no que se refere ao Ensino de Arte. Nos PCNs, como lembrado anteriormente, esses eixos são a reflexão, a fruição e a produção artística, e na PCSC constituem-se em contextualização, fruição e produção. Como se pode perceber, a leitura e ou fruição da imagem alicerçam as principais referências para as propostas pedagógicas em Arte.

A PCSC (1998, p. 195) propõe que o professor se aproprie de diferentes abordagens de leitura de imagem para trabalhar em sala de aula, por se entender que nenhuma sozinha dá conta do objeto a ser interpretado, devido ao seu caráter aberto e ambíguo. Entre as abordagens destacadas pela PCSC (1998, p.195-196) encontram-se: a sociológica (possibilita perceber como o artista estabelece uma comunicação entre o objeto e o grupo, suscitando sua participação na sociedade); semiológica (interpretar é perceber e compreender a dinâmica da construção e reconstrução de signos nos meios de comunicação e na produção cultural das sociedades); iconográfica (levanta características próprias do estilo, estuda o conteúdo e o significado do objeto artístico, observando sua forma); iconológica (procura entender o objeto artístico dentro de uma cultura, de uma filosofia ou de uma crença); estética (procura identificar o que há de universal presente no objeto artístico); gestáltica (analisa a estrutura formal). Entretanto, a PCSC (1998, p. 196) ressalta que é necessário que essa leitura transcorra através de passos metodológicos que auxiliam o aluno a adquirir a autonomia.

Esse posicionamento dos documentos oficiais estavam associados a abordagens metodológicas internacionais como as de Edmundo Feldman e de Michael Parsons. Entretanto, estudiosos brasileiros desenvolveram abordagens pensando o contexto brasileiro, destacando-se nesse cenário Terezinha Sueli Franz; Anamélia Bueno Buoro; e Sandra Regina Ramalho e Oliveira . 
Porém, nesta pesquisa, pôde-se perceber que os estudantes que estão concluindo o Ensino Médio, ainda demonstraram dificuldades em utilizar os conhecimentos específicos da linguagem visual no ato de ler, ou seja, não relacionam esses conhecimentos, desenvolvidos na escola, com os efeitos de sentido propostos pelas imagens. Nesta verificação, percebe-se, a efetivação da preocupação apontada por Ramalho e Oliveira, em fornecer subsídios mínimos para a formação de leitores críticos em relação às imagens do cotidiano.

Mesmo que os documentos oficiais, estudos e abordagens de leitura de imagens para o ensino de Arte venham sendo desenvolvidas no Brasil, o que se percebeu é que essas propostas ainda são pouco expressivas na formação dos estudantes na Educação Básica. Então, aponta-se para um outro questionamento: como articular esses estudos com a prática pedagógica?

Os jogos eletrônicos e as demais imagens em movimento fazem parte do cotidiano desses estudantes em idade escolar, mas a escola não os prepara como leitores nem para as imagens fixas, nem em movimento e muito menos para imagens digitais. Viuse que os estudantes têm domínio do computador e de seus recursos, assim a educação no contexto da cibercultura não se encontra apenas no âmbito do uso das tecnologias, mas, como ressalta Ramal (2002), em acompanhar a mutação dos processos comunicacionais e cognitivos que questionam as formas institucionais e culturais dos sistemas educacionais tradicionais.

Portanto, considerando que a aprendizagem se dá no espaço-temporal de interação, conforme Catapan (2001), o grande desafio para pesquisadores na área de Ensino de Arte, é entrar no jogo da formação de leitores de imagens digitais. Mas quais estratégias usar, quais características nossos "heróis" devem ter?

Esta é uma partida longa de um jogo que deve ser colaborativo, em que as relações entre as teorias e a prática pedagógica, entre as imagens e seus efeitos de sentido, entre ler e escrever visualmente, sejam elementos que movam as peças no tabuleiro de formar leitures críticos no âmbito da visualidade.

\section{Bibliografia:}

BARBOSA, Ana Mae. A Imagem no Ensino de Arte. São Paulo, Perspectiva; Porto Alegre, Fundação IOCHPE, 1991. 
CATAPAN, Araci Hack. Tertium: o novo modo do ser, do saber e do aprender (construindo uma taxionomia para medição pedagógica em tecnologia de comunicação digital). Tese (Doutorado em Engenharia de Produção) - Universidade Federal de Santa Catarina, Florianópolis, 2001.

COELHO NETTO, J.T. Semiótica, Informação e Comunicação. Perspectiva: São Paulo, 1983.

GREIMAS, A. J. Semiótica Figurativa e Semiótica Plástica. Revista Brasileira de Semiótica. n. 4. (1984). Traduzido por J. Assis da Silva, impressa em tipos datilográficos.

NÖTH, Winfried. A semiótica no século XX. Anablume: São Paulo, 1996.

OLIVEIRA, Ana Claudia. Lisibilidade da imagem. Revista da FUNDARTEC. v.1, n.1(jan./jun. 2001) Montenegro: FUNDARTEC, 2001.

RAMAL, Andréa Cecília. Educação na cibercultura: hipertextualidade, leitura, escrita e aprendizagem. Porto Alegre: Artmed, 2002.

RAMALHO E OLIVEIRA, Sandra Regina. Leitura de Imagens: uma busca de rizomas significantes. In: ENCONTRO NACIONAL DOS PESQUISADORES EM ARTES PLÁSTICAS, 14., 2005, Goiânia. Cultura Visual e desafios da pesquisa em artes. Goiânia, FAV/UFG, 2005, p. 430-439.

Imagem também se lê. São Paulo: Rosari, 2006.

. Leitura de imagens para a Educação. 1998. Tese (Doutorado em Comunicação e Semiótica) - Pontifícia Universidade Católica, São Paulo, 1998.

SANTA CATARINA. Secretaria de Estado da Educação e do Desporto. Proposta curricular de Santa Catarina: educação infantil, ensino fundamental e médio: disciplinas curriculares. Florianópolis: COGEN, 1998.

SAUSSURE, Ferdinand de. Curso de Lingüística Geral. Trad. Chelini, A, Paes, J. P. \& Salum, I. N. Cultrix: São Paulo, 1969. 